\title{
Interleukin-6 in relation to other proinflammatory cytokines, chemotactic activity and neutrophil activation in rheumatoid synovial fluid
}

\author{
Miek A van Leeuwen, Johanna Westra, Pieter C Limburg, Piet L C M van Riel, \\ Martin $H$ van Rijswijk
}

\begin{abstract}
Objective-To evaluate the relation between synovial fluid (SF) concentrations of interleukin-6 (IL-6) and other mediators of inflammation which are responsible for joint degradation in rheumatoid arthritis (RA).

Methods-We measured IL-6, IL-1及, tumour necrosis factor $\alpha$ (TNF $\alpha$ ), granulocyte macrophage colony stimulating factor, IL-8, and polymorphonuclear leucocyte (PMNL) chemotaxis and degranulation in SF from patients with RA $(n=30)$ in the early phase of the disease. Results-In a cross-sectional study IL-6 concentrations correlated with those of IL-1B, IL-8 and with PMNL activation as reflected by lactoferrin concentrations. In a longitudinal study, changes in IL-6 concentrations correlated with changes in TNF $\alpha, I L-8$ and lactoferrin concentrations.

Conclusion-IL-6 in SF appears to reflect the local proinflammatory, potentially erosive activity in RA. This supports the use of acute phase proteins, which are mainly induced by IL-6, as variables to monitor the course of RA.
\end{abstract}

(Ann Rheum Dis 1995; 54: 33-38)

Rheumatoid arthritis (RA) is a systemic inflammatory disease localised preferentially in the synovial joints. Chronic synovitis often leads to irreversible destruction of cartilage and periarticular bone. The inflamed synovium is characterised by infiltration of macrophages, $T$ and $B$ cells, and local proliferation of synoviocytes. The highly active macrophages and synoviocytes have been shown to be strong producers of cytokines, in particular the proinflammatory cytokines such as interleukin-1 (IL-1), tumour necrosis factor $\alpha$ (TNF $\alpha$ ), interleukin-8 (IL-8), granulocyte macrophage colony stimulating factor (GMCSF) and interleukin-6 (IL-6). ${ }^{1-5}$

Proinflammatory cytokines are thought to play a major role in chronic inflammation and joint destruction in RA. IL-1 and TNF $\alpha$ stimulate the proliferation of synoviocytes and the secretion of prostaglandins, collagenase, stromelysin, neutrophil proteases, and oxygen radicals, thus having potent catabolic actions on cartilage and bone. ${ }^{1}$ Both also induce the synthesis and secretion of other cytokines in the synovium, in particular IL-6 and IL-8. ${ }^{1} 24$ The activities of IL- 8 include chemotactic attraction and activation of polymorphonuclear leucocytes (PMNL). ${ }^{4}$ These PMNL, which may be present in large numbers in the synovial fluid, are thought to contribute to destruction of cartilage through the release of degradative enzymes.?

The local tissue damaging potential of IL- 6 is not clear; it does not, for example, stimulate the production of prostaglandin $E_{2}$ or proteinases by human synovial cells, and has no chemotactic properties. However, IL-6 is the major inducer of the systemic acute phase response, in particular of hepatic acute phase proteins. ${ }^{8}$ The acute phase response, as measured by the erythrocyte sedimentation rate (ESR) or $C$ reactive protein (CRP) concentrations, is commonly used in clinical practice to monitor disease activity. In previous studies a correlation between the course of clinical disease activity (as measured by joint swelling), serum concentrations of CRP, and progression of radiological joint damage has been demonstrated. ${ }^{9-11}$ Moreover, IL-6 concentrations in synovial fluid have been shown to be related to local disease activity in rheumatoid arthritis. ${ }^{12}$ The aim of the present study was to evaluate to what extent concentrations of IL- 6 in the synovial fluids of patients with early RA may be considered to be representative of those of the group of factors which are thought to play a major role in joint destruction.

\section{Patients and methods}

PATIENTS

One hundred consecutive patients attending the Department of Rheumatology, Groningen, who had rheumatoid arthritis (American Rheumatism Association (ARA) criteria) of disease duration less than one year, were invited to participate in a prospective follow up study. Disease onset was defined as the date on which the patient first presented complaining of the disease. Synovial fluid (SF) was obtained from 30 of these patients in an early phase of the disease during therapeutic arthrocentesis of actively inflamed painful swollen joints. In all cases corticosteroid (triamcinolone) was administered into the joint after aspiration of the SF. Fourteen patients had more than one aspiration early in the course of the disease, 
and 61 different samples (knee 54, shoulder 7) were available for analysis. Mean duration of the disease until the first aspiration was 21 months (range 3-50, median 17) and the mean time between two aspirations was seven months (range 1-25, median 7). All patients but one were rheumatoid factor positive. At the time of the aspiration, all patients were treated with non-steroidal anti-inflammatory drugs (NSAIDs) and 23 received disease modifying anti-rheumatic drugs (DMARDs) in addition (hydroxychloroquine $n=10$, i.m. gold $n=9$, d-penicillamine $n=4)$. Four patients were treated with low dose prednisolone.

SF samples were collected into sterile tubes with EDTA and immediately placed on melting ice. Cells were removed by centrifugation and $\mathrm{SF}$ were stored at $-20^{\circ} \mathrm{C}$ until use. Before assay each SF was treated with hyaluronidase (Sigma, type I-S, St Louis, MO) at a concentration of $10 \mathrm{U} / \mathrm{ml}$ for one hour at $37^{\circ} \mathrm{C}$ and then centrifuged at high speed to remove particles. Hyaluronidase treatment was performed to decrease the viscosity of the SF and to prevent the possible interference in the immunoassays of the combined presence of rheumatoid factor and hyaluronic acid. ${ }^{13}$

\section{CYTOKINE ASSAYS}

IL- 6 was determined by bioassay with the IL6-dependent mouse hybridoma cell line B9. ${ }^{14}$ Heat inactivated synovial fluid samples were serially diluted in medium consisting of RPMI1640 (Gibco BRL, Gaithersburg, MD) supplemented with $13 \%$ fetal calf serum, $60 \mu \mathrm{g} / \mathrm{ml}$, gentamycin, $2 \mathrm{mmol} / \mathrm{l}$ glutamin, $1 \mathrm{mmol} / 1$ sodium pyruvate and $50 \mu \mathrm{mol} / \mathrm{l}$ $\beta$-mercaptoethanol; $60 \mu \mathrm{l}$ test samples were added to 96 well culture plates (Costar, Cambridge, MA). Five thousand cells per well were added to a final volume of $100 \mu \mathrm{l}$ and cultured for 72 hours. Cell proliferation was measured in a colorimetric assay with MTTtetrazolium (Sigma) as described by Mosman. ${ }^{15}$ As standard we used recombinant human IL-6 $\left(10^{7} \mathrm{U} / \mathrm{mg}\right)$ from Genzyme (Boston, MA).

In addition, concentrations of IL-6 were determined with two different immunoassays. The first was an ELISA as described by Helle et $a l^{16}$ using a combination of the monoclonal antibody, mAb IL-6-16, and the polyclonal antibody, Sh-a-IL-6. The sheep anti-IL-6 was biotinylated using LC-biotin-N-hydroxysuccimide ester (Pierce, Rockford, IL) according to the manufacturer's instructions. SF were measured in four serial dilutions $(40-160-640-2560 \times)$ in the presence of an excess of normal sheep serum and after incubation the microplates were washed with phosphate buffered saline with $0.05 \%$ Tween-20 before incubation with streptavidine-horseradish peroxidase (HRPO) (Dakopatts A/S, Denmark) at 5000-fold dilution. Signal amplification was then performed by catalysed reporter deposition using 15 minutes of incubation with biotin-tyramine (BT) prepared as described by Bobrow according to method A. ${ }^{17} \mathrm{~A}$ second incubation with strepta-
vidine-HRPO ( $1000 \times$ dilution) for 15 minutes was performed. Ortho-phenyldiamine was added and after 20 minutes the reaction was terminated with $1 \mathrm{~mol} / 1 \mathrm{H}_{2} \mathrm{SO}_{4}$. The absorbance was read at $492 \mathrm{~nm}$ on a Titertek Multiscan. As standard we used recombinant human IL-6 (Genzyme) with a detection range of $0 \cdot 8-100 \mathrm{pg} / \mathrm{ml}$.

The second immunoassay for IL-6 in SF was an IL-6 enzyme amplified sensitivity immuno assay (EASIA) (kit by Medgenix Diagnostics, Fleurus Belgium). Monoclonal antibodies directed against distinct epitopes of IL-6 were used; samples were diluted 50-fold, standards were in the range $20-2000 \mathrm{pg} / \mathrm{ml}$. The colour reaction was performed with tetramethylbenzydine and hydrogen peroxide and absorbance was read at $450 \mathrm{~nm}$ and $490 \mathrm{~nm}$ on a Vmax EASIA reader. Data were calculated using a polychromatic data reduction method (kindly provided by Medgenix).

For measurement of IL-1 $\beta, T N F \alpha$ and GM-CSF in SF we used EASIAs (Medgenix) in which samples were tested undiluted, monoclonal antibodies were used and reading was according to the method used in the IL-6 EASIA. IL- $1 \beta$ and GM-CSF standards were in the range $25-2000 \mathrm{pg} / \mathrm{ml}, \mathrm{TNF} \alpha$ standards in the range $15-1500 \mathrm{pg} / \mathrm{ml}$. Soluble TNF receptors do not interfere with the detection of $\mathrm{TNF} \alpha$ in this EASIA, in which the same reagents are used as in the TNF-immunoradiometric assay (Medgenix). ${ }^{18}$

IL-1 $\beta$ in SF was also tested in a high sensitivity IL-1 $\beta$ ELISA kit (Cistron Biotechnology, Pinebrook, NJ). A monoclonal antibody was used as coating antibody and a polyclonal rabbit anti-IL-1 $\beta$ as detecting antibody. Samples were diluted fivefold and standards were in the range $5-150 \mathrm{pg} / \mathrm{ml}$; the lower limit of detection was $5 \mathrm{pg} / \mathrm{ml}$.

IL-8 in SF was determined using a human IL-8 immunoassay (Quantikine, $\mathrm{R} \& \mathrm{D}$ Systems, Abingdon, UK). A monoclonal antibody to IL- 8 was coated to the microtitreplate; the second antibody consisted of an HRPOlabelled polyclonal antibody. The standard consisted of recombinant human IL-8 used in concentrations of $25-3000 \mathrm{pg} / \mathrm{ml}$; samples were diluted 10 -fold.

\section{CHEMOTAXIS ASSAY}

Normal human PMNL were isolated from freshly drawn venous blood anticoagulated with EDTA, from the same donor for each assay. After density gradient centrifugation on Lymphoprep (Nycomed Pharma A/S, Oslo, Norway) neutrophils were separated from erythrocytes by lysis for 10 minutes with cold ammonium chloride $\left(155 \mathrm{mmol} / 1 \mathrm{NH}_{4} \mathrm{Cl}, 0 \cdot 1\right.$ $\mathrm{mmol} / \mathrm{LDTA})$. Cells were washed twice with $0.9 \%$ saline, once with Hanks's balanced salt solution (HBSS) (Gibco) and suspended in HBSS with $0.5 \%$ bovine serum albumin (HBSA) at $2 \cdot 510^{6}$ cells $/ \mathrm{ml}$. Cell viability was tested by Trypan Blue exclusion and was $>97 \%$.

Chemotaxis was measured according to Boyden, ${ }^{19}$ using blind well chambers (Neuro- 
probe, Cabin John, MD) with a volume of $200 \mu \mathrm{l}$ attractant or control medium in the bottom and $200 \mu \mathrm{l}$ cell suspension in the top compartment. The chambers were separated by a $13 \mathrm{~mm}$ diameter $3 \mu \mathrm{m}$ pore size polycarbonate filter (polyvinyl pyrrolidone free, Nuclepore Corporation, Pleasanton, CA). Before assay, filters were soaked in $0.5 \mathrm{~mol} / \mathrm{l}$ acetic acid for two minutes and then washed with HBSA. ${ }^{20}$ SF were measured at five twofold dilutions starting at $1: 10$; as control medium we used HBSA. Chambers were incubated for 45 minutes at $37^{\circ} \mathrm{C}$ in humidified $95 \%$ air $/ 5 \%$ carbon dioxide. After incubation the cells in the upper chamber were counted using a coulter counter. Chemotactic index (CTI) was expressed as the percentage of cells migrating towards the chemoattractant and was calculated as:

$$
\begin{gathered}
\mathrm{CTI}=100 \times[1-(\text { cells in sample well/cells } \\
\text { in control well })]
\end{gathered}
$$

Recombinant human IL-8 (Genzyme) was used as standard in the chemotaxis assay at concentrations of $0.5-50 \mathrm{ng} / \mathrm{ml}$, resulting in a linear dose-response relationship between the $\log$ of the IL- 8 concentration and the CTI from 1 to $20 \mathrm{ng} / \mathrm{ml}$ of IL-8. In addition to the SF samples, different combinations of recombinant human IL-8 $0 \cdot 3-30 \mathrm{ng} / \mathrm{ml}$ with TNF $\alpha 0.01-10 \mathrm{ng} / \mathrm{ml}$ or IL-1 $0.01-10 \mathrm{ng} / \mathrm{ml}$ or with both, were tested in the assay to evaluate possible synergism of the cytokines. Contribution of IL-8 to the chemotactic activity of SF was tested by performing the chemotaxis assay in the presence of an excess of neutralising monoclonal antibody to IL-8 (4 $\mu \mathrm{g} / \mathrm{ml}$ ) (clone 6217.11, R \& D Systems). Percentage inhibition was expressed as:

$100 \times[1-(C T I+$ anti IL-8/CTI - anti IL-8) $]$

\section{LACTOFERRIN AND IGM-RHEUMATOID FACTOR} ELISA

Lactoferrin concentrations were measured by ELISA as follows: microtitre plates were coated with $\left.\mathrm{F}(\mathrm{ab})_{2}\right)_{2}$-rabbit-anti-human-lactoferrin (Jackson Immunoresearch, Westbroke, PA). SF were tested in four dilutions (200-800-3200-12800 $\times$ ) and the conjugate was HRPO-rabbit-anti-human-lactoferrin (Jackson Immunoresearch). The standard consisted of a supernatant from activated PMNL and was in the range $0 \cdot 8-100 \mathrm{ng} / \mathrm{ml}$ lactoferrin. IgM rheumatoid factor (IgM-RF), which did not cross react in that ELISA was itself measured by ELISA as described before, ${ }^{21}$ on microtitre plates coated with aggregated human IgG and expressed as $\mathrm{IU} / \mathrm{ml}$, using a standard calibrated against the WHO standard.

\section{STATISTICS}

Correlations between the results of the IL- 6 assays were calculated using the Pearson test and correlations between the other biochemical parameters were calculated by Spearman test or multiple linear regression analysis. To compare a biochemical variable in two groups we used a two-tailed $t$ test.

\section{Results}

IL-6 MEASUREMENTS

IL-6 concentrations in all $61 \mathrm{SF}$ samples were measured with three assays. Hyaluronidase treatment had no influence on results of IL-6 measurements. Possible interference by IgMRF was unlikely because samples were measured in the presence of an excess of normal sheep serum; furthermore, there was no correlation between the SF concentrations of IL-6 and those of IgM-RF (present in concentrations of 5-850 (mean 153, median 65) IU/ml (data not shown)). The Pearson correlation coefficient between bioassay results and the EASIA was 0.915 , between bioassay and the IL-6 ELISA was $0 \cdot 809$, and between EASIA and ELISA was 0.890 (all highly significant: $n=61, p<0.001)$. For further calculations we used the IL- 6 values of the bioassay and the ELISA.

IL-1 $\beta$, GM-CSF, TNF $\alpha$ AND IL-8 ASSAYS

Table 1 shows the results of the cytokine measurements in the first SF sample of each patient $(n=30)$, including IL-6. Concentrations of IL-1 $\beta$ and GM-CSF were below the detection limit in all EASIA samples, but IL-1 $\beta$ was detectable in all ELISA samples. Positive results for TNF $\alpha$ and IL- 8 were obtained in all samples. There was no influence of hyaluronidase treatment on the results of these IL- $1 \beta, T N F \alpha$ and IL- 8 measurements.

\section{CHEMOTAXIS ASSAY}

This assay appeared to be sensitive, as $10 \mathrm{ng} / \mathrm{ml}$ IL-8 gave a mean CTI of 51.8 (SD $5 \cdot 8) \%$ in six different experiments with PMNL from the same donor. Mean CTI in the SF samples, tested in a dilution of $1: 20$, was $32.5 \%$ (2-62\%, median $30 \%$ ). In this $1: 20$ dilution, all SF samples yielded results within the linear range of the assay. Addition of TNF $\alpha$ or IL-1, or both, to a range of concentrations of IL-8 corresponding to those found in SF samples, did not increase the chemotactic response in this assay compared with IL-ô a'one (data not shown). Chemotaxis induced by an excess of recombinant human IL-8 (50-200 ng/ml), leading to a plateau of chemotaxis (CTI $60 \%$ ), was totally inhibited by addition of $4 \mu \mathrm{g} / \mathrm{ml}$ anti IL-8; that of SF (measured at 1:20 dilution) was inhibited by $22(28) \%$ (range $<5-77 \%$ ) in eight SF samples in either the presence or the absence of $4 \mu \mathrm{g} / \mathrm{ml}$ anti IL-8.

INTERRELATION BETWEEN IL-6 AND OTHER CYTOKINES, LACTOFERRIN AND CHEMOTAXIS IN SF

Table 2 shows the Spearman correlation matrix for the results of IL-6, IL-1 $\beta$, TNF $\alpha$, IL-8, lactoferrin, and chemotactic index, as measured in the first sample of each patient $(n=30)$. IL-6 correlated significantly with IL-1 $\beta(p<0.01)$ and IL-8 $(p<0.02)$, but not with TNF $\alpha(p>0 \cdot 1)$. In addition, a significant correlation $(p<0.001)$ was found between concentrations of IL- 6 and those of lactoferrin 
(present in concentrations of 1.3-67 (mean $14 \cdot 3$, median 9) $\mu \mathrm{g} / \mathrm{ml}$ ). A similar significance was found for the correlation between IL- 8 and lactoferrin concentrations, but correlations between CTI and individual cytokines or lactoferrin were not significant. Adding in the different cytokines as variables in a multiple regression analysis, no improvement in the prediction of the CTI was observed.

In 12 patients more than one aspiration of the same knee was necessary because of a flare of the arthritis in that joint. Patients with recurrent joint effusions appeared to have significantly greater concentrations of IL-6, IL-8, and lactoferrin (first SF sample from each patient) than patients with incidental knee swelling. The differences between the two groups could not be related to differences in treatment with DMARDs or prednisolone, which was similar for both groups.

In patients with recurrent swelling of the same joint, we analysed whether changes in IL-6 concentrations in the successive SF samples were related to changes in concentrations of other cytokines and lactoferrin by expressing the cytokine and lactoferrin values in the second and occasional third aspirate as percentages of the values in the first SF for each patient. In the sequential samples both higher and lower values were found compared with those in the first sample from an individual patient. The Spearman correlations between the relative changes in concentrations of IL-6 and IL-8, IL- 6 and TNF $\alpha$, IL- 6 and lactoferrin, and IL-8 and lactoferrin were significant $(\mathrm{n}=19, \mathrm{p}<0.05)$, whereas the correlation between the relative changes in concentrations of IL- 6 and IL- $1 \beta$ were not $(n=19, p>0 \cdot 2)$ (table 3).

Table 1 Concentrations of IL-6 (ELISA), IL-1 $\beta$, $T N F \alpha$, and IL-8 in synovial fluids of 30 patients with $R A$ (first sample of each patient)

\begin{tabular}{llll}
\hline & Median & Range & Interquartile range \\
\hline IL-6 (ng/l) & 26500 & $300-90000$ & $12000-44000$ \\
IL-1 $\beta$ (ng/l) & $45 \cdot 5$ & $5-246$ & $24 \cdot 5-63 \cdot 0$ \\
TNF $\alpha(\mathrm{ng} / \mathrm{l})$ & $58 \cdot 5$ & $10-295$ & $35 \cdot 0-92 \cdot 0$ \\
IL-8 $(\mathrm{ng} / \mathrm{l})$ & 1700 & $200-37300$ & $580-3270$ \\
\hline
\end{tabular}

Table 2 Correlations between cytokine concentrations, lactoferrin concentrations and chemotactic index in synovial fluids of 30 patients with rheumatoid arthritis

\begin{tabular}{|c|c|c|c|c|c|c|}
\hline & $I L-6 E$ & $I L-6 B$ & $I L-1 \beta$ & $T N F \alpha$ & $I L-8$ & $L F$ \\
\hline IL-1 $\beta$ & $0.522^{\star \star}$ & $0.480^{\star \star}$ & - & & & \\
\hline TNF $\alpha$ & $0 \cdot 160$ & 0.313 & $0 \cdot 302$ & - & & \\
\hline IL-8 & 0.449 & $0.524^{\star \star}$ & $0 \cdot 304$ & 0.369 & - & \\
\hline LF & $0.732^{\star \star \star}$ & $0.690^{\star \star}$ & $0.491^{\star \star}$ & 0.194 & $0 \cdot 794^{\star \star \star}$ & - \\
\hline CTI & $0 \cdot 249$ & $0 \cdot 228$ & $0 \cdot 224$ & 0.092 & $0 \cdot 347$ & 0.319 \\
\hline
\end{tabular}

IL-6E: ELISA; IL-6B: bioassay; IL-1 $\beta$ : ELISA-Cistron. LF = lactoferrin; CTI = chemotactic index. ${ }^{\star \star} \mathrm{p}<0.01,{ }^{\star \star \star} \mathrm{p}<0.001$.

\section{Discussion}

We examined the relationship between IL-6 and other proinflammatory cytokines, and neutrophil chemotaxis and activation in synovial fluids of rheumatoid arthritis patients, in order to analyse to what extent IL-6 concentrations in SF reflect those of other factors believed to be the main causes of bone and cartilage destruction in inflammatory arthritis.

We have confirmed previous reports ${ }^{22-25}$ of high concentrations of IL- 6 in SF of patients with RA. Our study comprised only patients with early RA, but no comparison of data related to disease duration could be made because most published studies did not mention the stage of the disease. Because previous studies used different methods or expressed results in arbitrary units and did not afford appropriate comparisons, we have compared three assays-a bioassay, a commercially available ELISA and one which is not commercially available-and have expressed our results in $\mathrm{ng} / \mathrm{ml}$, calibrated against a recombinant hu-IL-6 standard. Despite the use of different antibodies, no differences were found between the results of the two immunoassays. In addition, IL- 6 concentrations as measured with the immunoassays and the bioassay were similar, at both high and low ranges of detection, ${ }^{24}$ indicating that IL-6 detected with these assays was both specific and biologically active.

Several investigators have tested SF for the presence of IL-1 $\beta$ and have obtained conflicting results, depending on the method used. Most bioassays could not demonstrate IL-1, which was attributed, in part, to the presence of inhibitors such as IL-1 receptor antagonist. ${ }^{24} 26$ Our inability to demonstrate the presence of IL-1 $\beta$ with the EASIA (Medgenix) was in sharp contrast with the results obtained with the ELISA (Cistron). This contradiction appears not to be merely a consequence of differences in sensitivity of these assays: in about $50 \%$ of the samples the concentrations measured with the ELISA (Cistron) were $>50 \mathrm{pg} / \mathrm{ml}$ and thus above the detection limit of the EASIA (Medgenix). Differences in reagents or in sensitivity to cross reacting substances in SF may have contributed to differences between results from the two respective assays. Our ELISA (Cistron) results agree with those from other studies which used reagents from the same manufacturer. ${ }^{24}$ 26-28

Using an immunoassay having a sensitivity as low as $15 \mathrm{pg} / \mathrm{ml}$ and no known interference by soluble receptors, ${ }^{18}$ we detected TNF $\alpha$ in all our SF samples. Taking into account the differences in detection limits of the assays used in other studies, our results are in agreement with those reported previously. ${ }^{29-31}$

Although the local production of GM-CSF in rheumatoid synovitis has been demonstrated by several investigators, ${ }^{52}$ very few data concerning GM-CSF concentrations in SF have been published. Xu et $a l^{5}$ demonstrated GM-CSF-like activity in RA SF, but could not 
detect immunoreactive GM-CSF in SF using a radioimmunoassay with a sensitivity of 100 $\mathrm{pg} / \mathrm{ml}$. This in contrast with their results from synovial tissue culture supernatants, in which GM-CSF could be identified both with the radioimmunoassay and with a bioassay. Despite using a more sensitive immunoassay (detection limit $25 \mathrm{pg} / \mathrm{ml}$ ), we were not able to detect GM-CSF in any of the RA SF samples $(n=61)$. Using the same assay, we had been able to demonstrate GM-CSF in concentrations of $25-200 \mathrm{pg} / \mathrm{ml}$ in serum samples of an RA patient with Felty syndrome treated with recombinant human GM-CSF, ${ }^{33}$ and in supernatants of IL-1 stimulated fibroblast and RA synoviocyte cultures (data not shown).

IL-8 has been shown to be a potent chemotactic factor for PMNL. ${ }^{4}$ In our sensitive chemotaxis assay (CTI $\geqslant 2 \%$ ), the minimum concentration of recombinant-human-IL-8 for detection of chemotaxis was $0.4 \mathrm{ng} / \mathrm{ml}$, resulting in a lower detection limit in SF (dilution $1: 10$ ) of $4 \mathrm{ng} / \mathrm{ml}$. In our study the concentrations of IL- 8 in SF were in the range 0.2-36 (median $1 \cdot 0$ ) $\mathrm{ng} / \mathrm{ml}$. We found a weak correlation between IL- 8 concentration and chemotactic index, as described in other studies. ${ }^{34}$ This may be because the concentrations of immunoreactive IL-8 were greater than $4 \mathrm{ng} / \mathrm{ml}$ in only five of our SF samples; the amount of IL-8 in RA SF is probably not sufficient to account for the results of in vitro chemotaxis. In addition, we found no evidence of a possible synergism (in vitro) between IL- 8 and the other cytokines in the chemotaxis assay. It would appear that IL-8 in SF is not the only chemotactic factor responsible for the accumulation of PMNL in RA SF. ${ }^{34}$ This was supported by the results of control experiments in the presence of an excess of a neutralising monoclonal antibody to human IL-8. This concentration of antibody completely inhibited the chemotaxis induced by $200 \mathrm{ng} / \mathrm{ml}$ recombinant human IL-8, whereas the SFinduced chemotaxis was only inhibited by 22 $(28) \%$. This is in agreement with the results of Koch, ${ }^{4}$ who found that chemotactic activity was only partly inhibited after preincubation with anti-IL-8.

PMNL are a major source of enzymes, including those which are able to degrade cartilage. Lactoferrin is a PMNL-specific protein, which is released from the specific granules upon activation. The amount of lactoferrin in SF, rather than leucocyte or PMNL count, may therefore be considered as a measure of the degree of activation and local turnover of PMNL. ${ }^{35}$ Our method of processing the SF samples, with immediate chilling and rapid cell separation, does prevent activation or lysis of PMNL in vitro, so the lactoferrin concentrations may be considered to be representative of those in vivo.

The effects of IL-1 $\beta$, TNF $\alpha$ and IL-8 include activation of PMNL, but the relative contribution of these cytokines to this activation is not known. The highly significant correlation between IL-6 and lactoferrin concentrations suggests that concentrations of IL-6 in SF parallel the degree of local PMNL activation and turnover, regardless of the factors inducing this activation.

The results from sequential SF samples from the same patient suggest that relative changes in IL- 6 concentrations over time are accompanied by similar relative changes in IL-8, $\mathrm{TNF} \alpha$ and lactoferrin/PMNL activation but, surprisingly, not in IL-1 $\beta$. The reason for this difference with IL-1 $\beta$ is not clear from this study, as IL-1 is thought to be one of the major inducers of both IL-6 and IL-8. The concentration of IL-1 in SF reflects both local production and local consumption of IL-1; the biological availability of IL-1 depends on the simultaneous production of IL-1 receptor antagonist (IL-1 RA) ${ }^{36}$ and the change in balance between IL-1 and IL-1 RA over time. The same may be true for TNF $\alpha$ and soluble TNF-receptors. ${ }^{18}{ }^{37}$ However, it is not clear if the inhibitors of IL-1 and TNF $\alpha$ have a comparable biological role.

It can be concluded from the present results that IL-6 in SF of RA patients may be considered as an indicator for local proinflammatory and potentially erosive activity of proinflammatory cytokines, and PMNL activation. This supports the earlier findings that serum concentrations of acute phase proteins such as CRP, which are induced by IL-6, are related to the progression of radiologically demonstrable joint damage. ${ }^{11}$

We thank J Bijzet, $R$ van $W_{i j k}$ and $W$ Lolkema for technical assistance. EASIA reagents were kindly provided by $\mathrm{D}$ Radoux, Medgenix, Fleurus, Belgium. Dr L Aarden, CLB, Amsterdam, kindly provided the mouse hybridoma cell line $\mathrm{B} 9$, and $\mathrm{MAb}$ IL-6-16 and Sh-a-IL-6 antibodies.

This study was supported by a grant from Het Nationaal Reumafonds of The Netherlands.

1 Arend W P, Dayer J M. Cytokines and cytokine inhibitors or antagonists in rheumatoid arthritis. Arthritis Rheum 1990; 33: 305-15.

2 Guerne P A, Zuraw B L, Vaughan J H, Carson D A, Lotz $M$. Synovium as a source of interleukin 6 in vitro. f Clin Invest 1989; 83: 585-92.

3 Firestein G S, Alvaro-Garcia J M, Maki R. Quantitative analysis of cytokine gene expression in rheumatoid arthritis. F Immunol 1990; 144: 3347-53.

4 Koch A E, Kunkel S L, Burrows J C, et al. Synovial tissue macrophage as a source of the chemotactic cytokine IL-8. f Immunol 1991; 147: 2187-95.

$5 \mathrm{Xu} \mathrm{W} \mathrm{D,} \mathrm{Firestein} \mathrm{G} \mathrm{S,} \mathrm{Taetle} \mathrm{R,} \mathrm{Kaushansky} \mathrm{K,}$ Zvaifler N J. Cytokines in chronic inflammatory arthritis; II. Granulocyte-macrophage colony-stimulating factor in rheumatoid synovial effusions. F Clin Invest 1989; 83: 876-82.

6 Willems J, Joniau M, Cinque S, van Damme J. Human granulocyte chemotactic peptide (IL-8) as a specific neutrophil degranulator: comparison with other monokines. Immunology 1989; 67: 540-2.

7 Elford P R, Cooper P H. Induction of neutrophil-mediated cartilage degradation by interleukin-8. Arthritis Rheum 1991; 34: 325-32

8 Gauldie J, Richards C, Harnish D, Lansdorp P, Baumann $H$. Interferon $\beta_{2} / B$-cell stimulatory factor type 2 shares identity with monocyte-derived hepatocytestimulating factor and regulates the major acute phase stimulating factor and regulates the major acute phase
protein response in liver cells. Proc Natl Acad Sci USA protein response in
1987; 84: $7251-5$.

9 Amos R S, Constable T J, Crockson R A, Crockson A P, McConkey B. Rheumatoid arthritis: relation of serum $\mathrm{C}$-reactive protein and erythrocyte sedimentation rates to radiographic changes. $B M \mathcal{F} 1977$; i: $195-7$.

10 Möttönen T T. Prediction of erosiveness and rate of development of new erosions in early rheumatoid arthritis. Ann Rheum Dis 1988; 47: 648-53.

11 van Leeuwen $M$ A, van Rijswijk $M H$, van der Heijde D M F M, et al. The acute-phase response in relation to radiographic progression in early rheumatoid arthritis: a prospective study during the first 3 years of the arthritis: a prospective study during the first 3 years
disease. Br $\mathcal{F}$ Rheumatol 1993; 32 (Suppl 3): 9-13.

12 Miltenburg A M M, van Laar J M, de Kuiper R, Daha M R, Breedveld F C. Interleukin-6 activity in paired samples of synovial fluid. Correlation of synovial fluid interleukin-6 levels with clinical and laboratory parameters of inflammation. Br $\mathcal{F}$ Rheumatol 1991; 30: 
13 Faaber P, van den Bersselaar L A M, van de Putte L B A van den Berg W B. Immune complex formation between IgM rheumatoid factor and IgG generated by hyaluronic acid. Arthritis Rheum 1989; 32: 1521-7.

14 Aarden L A, de Groot E R, Schaap O L, Lansdorp P M. Production of hybridoma growth factor by human monocytes. Eur F Immunol 1987; 17: 1411-6.

15 Mosman T. Rapid colorimetric assay for cellular growth and survival: application to proliferation and cytotoxicity assays. F Immunol Methods 1983; 65: 55-63.

16 Helle M, Boeije L, de Groot E, de Vos A, Aarden L A. Sensitive ELISA for Interleukin-6. Detection of IL-6 in biological fluids: synovial fluids and sera. 7 Immunol biological fluids: synovial

17 Bobrow M N, Harris T D, Shaughnessy K, Litt G J. Catalyzed reporter deposition, a novel method of signal amplification. F Immunol Methods 1989; 125: 279-85.

18 Engelberts I, Stephens S, Francot G J M, van der Linden $\mathrm{C} J$, Buurman W A. Evidence for different effects of soluble TNF-receptors on various TNF measurements in human biological fluids. Lancet 1991; 338: 515-6.

19 Boyden S. The chemotactic effect of mixture of antibody and antigen on polymorphonuclear leucocytes. F Exp Meth 1962; 115: 453-66.

20 Dejana E, Bussolino F, Wang J M, Mantovani A. Cytokine regulation of endothelial cells. In: Blackwell $F \mathrm{R}$, editor Cytokines, a practical aproach. New York: Oxford University Press, 1991; 217-9.

21 van Leeuwen $M$ A, Westra J, Limburg P C, et al. Quantitation of IgM, IgA and IgG rheumatoid factors b ELISA in rheumatoid arthritis and other rheumatic disorders. Scand $\mathcal{F}$ Rheum 1988; 75 (Suppl): 25-31.

22 Bhardwaj N, Santhanam U, Lau L L, et al. IL-6/IFN-b2 in synovial effusions of patients with rheumatoid arthritis and other arthritides. Identification of several isoforms and studies of cellular sources. F Immunol 1989; 143: 2153-9.

23 Brozik M, Rosztoczy I, Meretey K, et al. Interleukin 6 levels in synovial fluids of patients with different arthritides: correlation with local IgM rheumatoid factor and systemic acute phase protein production. $\mathcal{F}$ Rheumatol 1992; 19: acute

24 Holt I, Cooper R G, Denton J, Meager A, Hopkins S J. Cytokine inter-relationships and their association with disease activity in arthritis. $\mathrm{Br} \mathcal{F}$ Rheumatol 1992; 31 725-33.

25 Houssiau F A, Devogelaer J P, van Damme J, de Deuxchaisnes C N, van Snick J. Interleukin-6 in synovial fluid and serum of patients with rheumatoid arthritis and other inflammatory arthritides. Arthritis Rheum 1988, 31: $784-7$.

26 di Giovine F S, Poole S, Situnayake R D, Wadhwa $M$ Duff G W. Absence of correlations between indices of systemic inflammation and synovial fluid interleukin 1 alpha and beta) in rheumatic diseases. Rheumatol $I n$ 1990; 9: 259-64.

27 Kahle P, Saal J G, Schaudt K, Zacher J, Fritz P, Pawalee G. Determination of cytokines in synovial fluids: correlation with diagnosis and histomorphological characteristics of synovial tissue. Ann Rhewn Dis 1992 51: $731-4$.

28 Rooney M, Symons J A, Duff G W. Interleukin 1 beta in synovial fluid is related to local disease activity in synovial fuid is related to local disease activity in

29 Saxne T, Palladino M A, Heinegard D, Talal N, Wollheim F A. Detection of tumor necrosis factor $\alpha$ bu Wollheim F A. Detection of tumor necrosis factor $\alpha$ but
not tumor necrosis factor $\beta$ in rheumatoid arthritis synovial fluid and serum. Arthritis Rheum 1988; 31: 1041-5.

30 Tetta C, Camussi G, Modena V, Di Vittorio C, Baglioni C. Tumour necrosis factor in serum and synovial fluid of patients with active and severe rheumatoid arthritis. $A n$ Rheum Dis 1990; 49: 665-7.

31 Westacott C I, Whicher J T, Barnes I C, Thompson D, Swan A J, Dieppe P A. Synovial fluid concentration of five different cytokines in rheumatic diseases. Ann Rheum Dis 1990; 49: 676-81.

32 Alvaro Garcia J M, Zvaifler N J, Brown C B, Kaushansky K, Firestein G S. Cytokines in chronic inflammatory Firestein $G$ S. Cytokines in chronic inflammatory arthritis. VI. Analysis of the synovial cells involved in GMCSF production and gene expression in rheumatoid arthritis and its regulatic

33 Hazenberg B P C, van Leeuwen M A, van Rijswijk M H Stern A C, Vellenga E. Correction of granulocytopenia in Felty's syndrome by granulocyte-macrophage colonystimulating factor. Simultaneous induction of interleukin6 release and flare-up of the arthritis. Blood 1989; 74: 2769-70.

34 Brennan F M, Zachariae C O C, Chantry D, ot al. Detection of interleukin-8 biological activity in synovial fluids from patients with rheumatoid arthritis and production of interleukin-8 mRNA by isolated synovial cells. Eur $\mathscr{f}$ interleukin-8 mRNA by isol.

35 Mansson B, Geborek P, Saxne T, Björnsson S. Cytidine deaminase activity in synovial fluid of patients with rheumatoid arthritis: relation to lactoferrin, acidosis, and cartilage proteoglycan release. Ann Rheum Dis 1990; 49: 594-7.

36 Koch A E, Kunkel S L, Chensue S W, Haines G K Strieter R M. Expression of interleukin-1 and interleukin-1 receptor antagonist by human rheumatoid synovial tissue macrophages. Clin Immunol Immunopathol 1992; 65: 23-9.

37 Roux-Lombard P, Punzi L, Hasler F, et al. Soluble tumor necrosis factor receptors in human inflammatory synovial fluids. Arthritis Rheum 1993; 36: 485-9. 